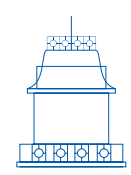

RESEÑ A

\title{
Benjamin, A. \& Vardoulakis, D. (Eds.). (2015). Sparks Will Fly: Benjamin and Heidegger. SUNY Press: New York, 291 pp.
}

\author{
Tatiana Staroselsky \\ Universidad Nacional de La Plata, La Plata, Argentina \\ E-mail: staroselskytatiana@gmail.com | ORCID: 0000-0002-9380-4088 \\ https://doi.org/10.17533/udea.ef.n61a12
}

Entre Martin Heidegger y Walter Benjamin hay, es sabido, diferencias biográficas y políticas muy marcadas, que oponen sus trayectorias muy fuertemente. Tal vez por el peso histórico de estas diferencias, y fundamentalmente por el modo en que la relación con el nazismo adquiere prelación en ambos casos para dar cuenta de los recorridos intelectuales, la relación entre los autores, que estructura el volumen que reseñamos, no fue explorada sistemáticamente en el marco de las interpretaciones, cuantiosas y muy variadas, de las ideas de cada uno de ellos. No obstante, y como notó muy tempranamente Hannah Arendt (1990), 'entre sus escritos pueden encontrarse puntos de contacto muy llamativos, que fueron señalados luego por algunos intérpretes aislados y que resultaron, asimismo, indignantes para otros tantos.

En este marco, la aparición de este volumen, disponible por el momento sólo en inglés, es significativa, ya que, escapando de la búsqueda de coincidencias y diferencias aisladas, logra hacer hincapié en la productividad que un diálogo -mayormente póstumo- entre estos pensadores puede tener para nuestro presente. Conscientes de este logro, los editores titulan el libro a partir de una expresión que emplea el mismo Benjamin. En efecto, el 20 de enero de 1930, en una carta a su amigo Gershom

1 Allí, la autora sostiene que Benjamin "tenía en realidad más en común con Heidegger de lo que lo hizo con las sutilidades dialécticas de sus amigos marxistas" (Arendt, 1990, p. 186). 
Scholem, refiriéndose al proyecto del Libro de los pasajes, colección de apuntes, citas y fragmentos que consideraba su obra maestra y en la que trabajó intermitentemente desde 1927 hasta su muerte en 1940, Benjamin refiere que encontrará a Heidegger en su camino, y que espera que surjan algunas chispas del choque entre el modo heideggeriano de considerar la historia y el suyo propio.

Con este espíritu, entonces, el libro comienza, en la introducción a cargo de los editores, por marcar las diferencias biográficas entre los autores, que son también diferencias políticas muy profundas, para, a partir de allí, llevar a cabo un esfuerzo colectivo y sostenido por acercar sus ideas. Sin embargo, y vale la pena enfatizar este mérito, acercar no será aquí señalar similitudes ni conciliar, sino que significará una jugada mucho más arriesgada: poner a estos dos grandes de la filosofía, a su manera revolucionarios (Benjamin para la tradición ligada al marxismo, Heidegger para la fenomenología y la hermenéutica), a discutir frente a frente.

Y como es esperable, para que este encuentro tenga lugar hace falta realizar, en primer lugar, el ejercicio de delimitar (o fundar) un espacio de diálogo y discusión, o varios. Es así que, compuesto por once capítulos, y con los aportes de once autores, el libro se estructura en torno a cinco apartados temáticos que demarcan cinco campos de intereses compartidos.

El primero se titula "Conocimiento" ["Knowledge"] y abre con "Entanglement-of Benjamin with Heidegger" de Peter Fenves. Allí, se trabaja a partir de un descubrimiento: Benjamin y Heidegger se encontraron en 1913 en el marco de un seminario a cargo de Heinrich Rickert que exploraba la diferencia entre la mera vida [bare life, bloßes Leben] y la vida completa o llena [completed life, vollendetes Leben]. El punto de partida del autor es claro: no buscará influencias de un autor sobre el otro y describirá, en cambio, un cierto enredo [entanglement] a partir de una serie de puntos de correlación que muestran la proximidad de sus líneas de pensamiento -como partes de un mismo entramado, de un cierto sistema-, tanto como la divergencia del sentido y la dirección en que estas líneas se mueven. A partir de la coincidencia en el seminario, el diálogo con Rickert se hace patente en sus producciones: en la adaptación de la terminología, en la elección de los temas y, centralmente, en el rechazo que elaboran y el desmantelamiento que ambos operan en la década del 20 del concepto mismo de vida completa en el marco del campo de tensiones que éste forma con el nihilismo nietzscheano.

El segundo capítulo, "Critique and the Thing. Benjamin and Heidegger", a cargo de Gerhard Richter, comienza enfatizando la importancia que en la obra de ambos reviste el deseo de aproximarse rigurosamente a los fenómenos a través del lenguaje entendido como condición de posibilidad del pensary da cuenta, desde allí, de un conjunto de preocupaciones comunes que lo exceden. Entre ellas, la recuperación del criticismo kantiano -y de la práctica de la crítica - en un ámbito diferente del neokantiano será clave: en Benjamin, la crítica estará orientada a la búsqueda del contenido de verdad de una obra, y será el lugar de contacto, vía Schlegel, entre la filosofía y la historia. A su vez, comprendida como un compromiso de revisión y de reinvención de los propios métodos y enfoques ante cada 
nuevo objeto, la crítica será la clave que le permitirá a Benjamin habérselas con el mundo de las cosas. En Heidegger, la crítica tiene un papel menos protagónico o menos explícito. Aun así, su proyecto implica un cuestionamiento de formas osificadas de pensar y actuar que puede ser leído como una forma post-kantiana de crítica (es decir, no centrada en el sujeto), que busca acercar el pensamiento a las cosas del mundo -las herramientas tanto como las obras de arte-. Para ambos, sostiene Richter, la crítica es parte de una política de la pregunta, que se aleja de ser un mero juicio y resulta una vía hacia la verdad: su positividad, su capacidad de afirmación, no puede ser mayor.

La segunda parte del libro, centrada en la experiencia, se compone de dos capítulos. El primero, a cargo de Ilit Ferber, se titula "Stimmung. Heidegger and Benjamin" y rastrea los modos en que Benjamin y Heidegger redefinieron la experiencia y el conocimiento en términos que se alejan del par tradicional sujeto-objeto y que tienen como centro el estado de ánimo² [Stimmung]. Ambos elaboran, muy explícitamente, una crítica a la forma tradicional de conceptualizar la relación del hombre con el mundo y buscan dar cuenta de ella de un modo radicalmente otro que desafía a la estructura de la intencionalidad. En Heidegger, Dasein y mundo se implican en estructuras complejas como la del estar-en-el-mundo, en las que el estado de ánimo y la disposición anímica aparecen no como tonalizadores, sino como condiciones de posibilidad del aparecer de las cosas. Es lo que ocurre, para Benjamin, con la melancolía, en la que el mundo se revela de una forma específica.

En "Commodity Fetichism and the Gaze" Kiarina Kordela recupera los trabajos de Comay y Caygill para relacionar a Benjamin y a Heidegger a través de Marx y Lacan. En realidad, Benjamin se acercará a estos pensadores y Heidegger quedará en las antípodas. La mirada y el fetichismo de la mercancía acercarán a Benjamin y a Marx, en tanto en ambos aparece una indeterminación de los sujetos y los objetos: en el antihumanismo de Benjamin las cosas devuelven la mirada, siendo en alguna medida agentes. En Marx, la mercancía es antropomorfizada en un intento del hombre de no volverse consciente de su propio carácter de objeto. Por otro lado, y mientras que Benjamin se aproxima a Lacan en su certeza de que siempre hay un exceso inconsciente en la historia, Heidegger puede ser pensado como continuando la tradición hegeliana por su creencia en la posibilidad del advenimiento de la conciencia plena y por su tratamiento de la autenticidad. Aun así, la relación entre el tratamiento que ambos proporcionan de la mirada permite a la autora llegar a conclusiones sobre el mundo contemporáneo, su arte, su política y sus formas propias de experiencia que los exceden.

La tercera parte del libro tiene su centro en la conceptualización del tiempo. Paula Schwebel analiza, en "Monad and time. Reading Leibniz with Heidegger and

2 Como recuerda la autora, siguiendo a Leo Spitzer, el término alemán "Stimmung" es virtualmente intraducible, en tanto términos como "estado de ánimo" o "humor" tienden a privilegiar el aspecto subjetivo del concepto, que no refiere sólo a él sino también a las condiciones ambientales. 
Benjamin", el modo en que las interpretaciones que ambos filósofos esbozaron de la monadología en 1928 -influenciados por su lectura común de Husserl- pueden iluminar las diferencias que pueblan sus filosofías de la historia. Si bien ambos añaden tiempo a la unidad de Leibniz, mientras que para Benjamin la mónada está plagada de un tiempo no cronológico, para Heidegger ella misma origina el tiempo. Esta diferencia en la apropiación de las ideas de Leibniz se prolonga y profundiza en la obra de ambos hasta llegar a una comprensión radicalmente diferente del pasado, que es para Heidegger algo clausurado -que puede ser recuperado por el Dasein- y para Benjamin una instancia no clausurada que puede abrirse en la rememoración. Las consecuencias políticas que demarca esta diferencia en el modo de comprender el pasado y en general el tiempo histórico, de gran relevancia para la lectura conjunta de estos dos pensadores, son puestas en la mira también por Andrew Benjamin en el capítulo a su cargo, "Time and Task. Benjamin and Heidegger showing the present", donde la relación entre tiempo y política en torno a una ontología del presente, esto es, a la posibilidad de pensar o abrir filosóficamente el presente, resulta central. En este marco, la apuesta del autor consiste en conectar la obra de ambos filósofos en torno a cómo han conceptualizado la relación entre la experiencia, la política y el tiempo. Para esta tarea, analizará en el caso de Heidegger la conceptualización del presente, de aquello que se muestra y de la experiencia, tanto como la tarea filosófica autoasignada de pensar el ser sin acudir a la metafísica. En torno a Benjamin, rastreará el modo en el que piensa la relación entre tiempo y política, y entre progreso y tradición, a través de la utilización de conceptos teológicos y del método del montaje como una forma de constituir el presente que implica una destrucción.

La cuarta parte del libro está dedicada a Hölderlin e intenta establecer un puente entre los filósofos a partir de su interés común por su poesía. El primero de sus dos capítulos, "Walter Benjamin, Martin Heidegger, and the Poet", de Antonia Egel, tras dar cuenta de que ambos lograron, a través de lo que dijeron sobre el poeta, ir más allá de un mero análisis de su obra logrando una lectura productiva para sus propios desarrollos teóricos, avanza hacia algunas otras coincidencias y algunas diferencias relevantes. Benjamin -a las puertas de la primera guerra mundial y tras el suicidio de dos amigos- elige dos poemas que lidian con la pregunta por el lugar del poeta en el mundo, y encuentra allí una nueva manera de comprender la poesía como una forma de muerte y la muerte -en un nuevo significado- como una forma de poesía. Heidegger encuentra la poesía de Hölderlin escapando de la política, huyendo tanto de su propia responsabilidad en el estado de las cosas como de las angustias que este le significaba, y se concentra en los poemas que refieren al movimiento y al tiempo. La diferencia que se demarca, radical, es que mientras Heidegger ve en la poesía una alternativa a la política, Benjamin parece comprender, antes de denunciarlos explícitamente, los peligros de la estetización de la política.

El segundo capítulo de esta sección, y octavo del libro, es "Sobriety, Intoxication, Hyperbology. Benjamin and Heidegger Reading Hölderlin". En él, Joanna Hodge 
parte de poner en diálogo las lecturas que ambos autores hicieron de los poemas de Hölderlin, pero despega, a través de su propia escritura, más allá de ellas. Atendiendo a aquellos entrelugares que se generan en las fronteras entre la poesía y la filosofía, y entre la religión y la política, Hodge indaga las fuerzas que allí se tensan en tanto fuerzas que el poeta y sus dos lectores se esforzaron por descubrir o acaso, al menos, mostrar. La autora destaca como parte de las preocupaciones conjuntas de estos tres pensadores la urgencia por complejizar la conceptualización de lo humano como tal y, específicamente, por imaginar qué será de lo humano tras las modificaciones de la experiencia de las que son $-y$, como se enfatiza en el texto, somos aún- testigos. En este contexto, dos elementos se develan centrales, a saber, por un lado, el lenguaje y, por el otro, lo monstruoso, como aquellos límites que la filosofía, la poesía y acaso también la política no pueden evitar desafiar.

El último apartado del libro se hace cargo de una de las áreas de mayores y más relevantes diferencias entre Benjamin y Heidegger, a saber, la política. "Politics" cuenta con cuatro capítulos, el primero de los cuales, a cargo de Krzysztof Ziarek, se titula "Beyond Revolution. Benjamin and Heidegger on Violence and Power". La crítica de la violencia mítica de Benjamin, atravesada por el mesianismo, y su defensa de la violencia divina o pura son puestas a conversar con las reflexiones de Heidegger sobre el poder, la justicia y el derecho. El autor encuentra en ambos filósofos un esfuerzo de pensar una vida más allá de la violencia: en Benjamin, en la conceptualización de un tipo de violencia no violenta; en Heidegger, en la posibilidad de un reinar sin violencia [das Gewalt-lose Walten] basado en una comprensión alternativa del poder que lo aleja de la esfera del dominio y la soberanía, y lo vincula con la gentileza [Milde]: lo revolucionario será la potencialidad de originar una novedad, o al menos interrumpir un curso de acción desde un lugar diferente al del poder, a saber, desde el suspender o dejar.

Dimitris Vardoulakis hace hincapié en la relación entre arte y política en "A Matter of Inmediacy. The Political Ontology of the Artwork in Benjamin and Heidegger". Allí, plantea que los textos que ambos escriben sobre el arte, lejos de limitarse al arte, se alzan como manifiestos contra la inmediatez, estructurados en torno a la recuperación, en el caso de Heidegger, de la tradición griega y, en el de Benjamin, de algunos temas románticos. En ambos casos, señala Vardoulakis, la respuesta a la inmediatez negará la autonomía del arte tanto como la autonomía de la política, e implicará una tarea: en Heidegger, la construcción o la fundación de algo nuevo que mira al futuro; en Benjamin, la politización del arte y de la vida que reniega de las utopías y hace pie en el pasado oprimido.

Cerrando el apartado sobre política, y con él el libro, Davis Ferris pone el foco, en "Politics of the Useless. The Work of Art in Benjamin and Heidegger", en el modo en que tanto Benjamin como Heidegger rechazaron la visión del arte como una actividad meramente representativa y se preguntaron por su significado y su valor una vez puesta en cuestión la pregunta por su utilidad. En este contexto, el autor encuentra que Benjamin pone el eje de la discusión en la función del arte, mientras que Heidegger va más allá y relaciona 
el significado del arte con el aparecer de una verdad.

A partir del rastreo de un encuentro real, a saber, aquel en el seminario de Rickert, el volumen da cuenta de encuentros de todo tipo, y se permite abrir diálogos allí donde las diferencias suelen resolverse con dicotomías estancas. El resultado es un trabajo cuya productividad no se agota en las interpretaciones de la obra de Benjamin y de Heidegger, que de todos modos complejiza y en las que introduce novedades, sino que las excede poniendo el eje en los problemas. Se trata entonces de un libro sobre Benjamin y Heidegger, pero se trata también de un libro sobre arte, historia, política y poesía que, a partir de la lectura dialógica de dos de los filósofos más importantes del siglo XX, se permite continuar su legado y lo hace, no museificando sus ideas y manteniéndolas intocadas para asegurar su más pulcra transmisión, sino trabajando con esas ideas para seguir tratando de echar luz sobre el presente. Tratándose de dos filósofos que, como vislumbró Arendt (1990), se esforzaron por alejarse de una cierta tradición filosófica que descansaba en una metafísica de la presencia y una epistemología de la representación, el resultado son una serie de intentos de seguir aquel viejo consejo de Rickert que marcó los recorridos de sus dos célebres alumnos: si queremos filosofar tenemos que aprender a pensar de un modo totalmente diferente.

\section{Referencias}

Arendt, H. (1990). Walter Benjamin. 1892-1940. En H. Arendt, Hombres en tiempos de oscuridad. Barcelona: Gedisa. 